\title{
MOLYBDENUM TRIOXIDE THIN FILMS DOPED WITH GOLD NANOPARTICLES GROWN BY A SEQUENTIAL METHODOLOGY: PHOTOCHEMICAL METAL-ORGANIC DEPOSITION (PMOD) AND DC-MAGNETRON SPUTTERING
}

\author{
C. CASTILLO I, G. BUONO-CORE*I, C. MANZUR ${ }^{1}$, N. YUTRONIC ${ }^{2}$, R. SIERPE ${ }^{2}$, G. CABELLO ${ }^{3}$, B. CHORNIK ${ }^{4}$.
}

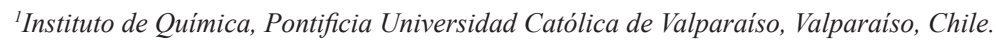 \\ ${ }^{2}$ Departamento de Química, Facultad de Ciencias, Universidad de Chile. \\ ${ }^{3}$ Departamento de Ciencias Básicas, Facultad de Ciencias, Universidad del Bío-Bío, Chillán, Chile \\ ${ }^{4}$ Departamento de Física, Facultad de Ciencias Físicas y Matemáticas, Universidad de Chile.
}

\begin{abstract}
Gold nanoparticles (AuNPs) were deposited by DC-magnetron sputtering onto molybdenum trioxide $\left(\mathrm{MoO}_{3}\right)$ thin films grown by Photochemical MetalOrganic Deposition (PMOD) on $\mathrm{Si}(100)$ and borosilicate glass substrates. The chemical, optical and morphology properties of the films were studied by UV/ Vis Spectroscopy, Scanning Electron Microscopy (SEM), X-Ray Photoelectron Spectroscopy (XPS), and X-Ray Diffraction (XRD). SEM revealed that AuNPs formed after $5 \mathrm{~s}$ of sputtering. AuNPs are spherical and have both an average diameter of $18 \mathrm{~nm}$ and a relatively narrow size distribution. As the deposition time increases, larger structures are formed by an aggregation of AuNPs. XPS studies of the AuNP/MoO films on $\mathrm{Si}(100)$ showed the presence of Mo(VI) and Mo(V), which indicated that the films were primarily non-stoichiometric molybdenum oxides. The occurrence of oxygen vacancies in the substrate play an important role to stabilize the AuNPs.
\end{abstract}

Keywords A. oxides, A. thin films, A. nanostructures, B. sputtering; C. x-ray diffraction, C. photoelectron spectroscopy

\section{INTRODUCTION}

Unique properties can be achieved by reducing a material to the nanometer scale. Metal nanoparticles (MNPs) present attractive optical, electronic, magnetic and chemical properties, among others, which are not displayed in the bulk state ${ }^{1,2}$. Gold nanoparticles (AuNPs) are the most stable MNP; they can be synthesized with different sizes and shapes; and they are easily functionalized with diverse ligands ${ }^{3}$. AuNPs have numerous applications in nanomedicine ${ }^{4,5}$, biotechnology ${ }^{6}$, microelectronics ${ }^{7}$, optics ${ }^{8-10}$, gas sensing ${ }^{11-13}$ and catalysis 14-20.

AuNPs have been prepared using various approaches that can be divided into physical and chemical methods. Included among the chemical methods are reduction ${ }^{21}$, photochemistry using UV irradiation ${ }^{22,23}$, photochemistry using X-ray irradiation ${ }^{24}$, sonochemistry ${ }^{25,26}$, and sonoelectrochemistry ${ }^{27}$ A physical method that can be used is cathodic deposition using magnetron sputtering. This physical method has several advantages over chemical syntheses, such as a lack of surface contamination from solvent or precursor molecules, which may be important for subsequent assays and/or applications. Furthermore, physical deposition is cheaper and faster and does not damage the environment ${ }^{28-30}$.

Gold catalysts with selected support materials can efficiently promote many reactions that normally occur at much higher temperatures or with lower selectivity when catalyzed by other metals. It has been shown that AuNPs supported on metal oxides exhibit unique activity at room temperature because of a meta-stable interatomic bonding between gold atoms ${ }^{31}$. It has been shown that substrates such as ceria ${ }^{32}$, titania ${ }^{33,34}$ and titanates ${ }^{35}$ can stabilize AuNPs in which oxygen vacancies play an important role in the stabilizing effect. It is generally accepted that interfaces provide adequate sites for chemical reactions, and metallic Au surfaces are required as reservoirs for a determined reactant ${ }^{36,37}$. Gold nanoparticles also play an important role in the development of chemical and biological sensors. A sensor usually has two functional components: one component selectively binds with the analyte, and the other provides transduction of this interaction into a detectable signal ${ }^{38}$. Considering the chromogenic properties of molybdenum oxide on the one hand and the catalytic properties of gold nanoparticles on the other, a binary system that is formed by molybdenum oxide coated with gold nanoparticles could potentially be of use in the field of catalysis and/or in the fabrication of new specific sensors. For example, it has been found that the UV-light coloration performance of $\mathrm{MoO}_{3}$ thin films can be enhanced by modification of the $\mathrm{MoO}_{3}$ surface with gold nanoparticles ${ }^{39}$. In this work, the synthesis and characterization of a AuNPs/ $/ \mathrm{MoO}_{3}$ system is examined. To synthesize the support material, i.e., molybdenum oxide, a pure photochemical deposition method such as PMOD is used, followed by the synthesis of AuNPs using a
DC-magnetron sputtering method. The synthesis of $\mathrm{MoO}_{3}$ thin films deposited onto $\mathrm{Si}(100)$ by $\mathrm{PMOD}$, has been described at length in a previous publication from our group ${ }^{40}$.

\section{Materials and methods}

2.1 General procedure

X-ray photoelectron spectra (XPS) were recorded on an XPS-Auger Perkin Elmer electron spectrometer Model PHI 1257 in an ultra-high vacuum chamber, with a hemispherical electron energy analyzer and an Al $\mathrm{K} \alpha \mathrm{X}$-ray source $(h v=1486.6 \mathrm{eV})$. The pressure of the spectrometer during data acquisition was maintained at $10^{-9}$ mbar. The binding energy (BE) scale was calibrated using adventitious carbon set to $284.8 \mathrm{eV}$. The accuracy of the $\mathrm{BE}$ scale was $\pm 0.1 \mathrm{eV}$. High resolution spectra were fitted using GaussianLorentzian curves and a Shirley background ${ }^{41}$. The approximate composition of the surface was determined for each element by dividing the individual peak area, after appropriate background subtraction, by their respective atomic sensitivity factors (ASF). XRD patterns were obtained using a Bruker D8 Advance diffractometer. The X-ray source was $\mathrm{Cu} 40 \mathrm{kV} / 40 \mathrm{~mA}$. The surface plasmon resonance (SPR) effect of AuNPs on Mo oxide films was examined by solid-state UV-Vis spectrophotometry from 200 to $800 \mathrm{~nm}$. References of barium sulfate $\left(\mathrm{BaSO}_{4}\right)$ and a Mo oxide thin film deposited onto quartz were used. The equipment used was a Shimadzu UV-2450 spectrophotometer with an integrating sphere ISR-2200 and controlled by the UVProbe software version 1.10. First, the diffuse reflectance of the samples was measured; then, via the Kubelka-Munk mathematical transformation, all absorbances were obtained. Scanning electron microscopy (SEM) images were obtained on a LEO $1420 \mathrm{VP}$ at an accelerating voltage of $25 \mathrm{kV}$ and coupled to an energy dispersive analysis instrument, Oxford 7424 model. For FE-SEM images a Leo Zeiss Supra 35-VP model was used with accelerating voltages of $15 \mathrm{kV}$ and $2 \mathrm{kV}$. Samples were prepared by coating the molybdenum trioxide thin films with Au nanoparticles through the sputtering method with deposition times of $1,2,3,4,5$ and $20 \mathrm{~s}$. The total count of Au nanoparticles on the oxide was evaluated using SEM images. A histogram was built with the Origin 8 software with a Gaussian fit analysis. Mathematical treatments of the average sizes with standard deviations were calculated by this program.

\subsection{Materials}

A gold target (Quorum Technologies Ltd.) was cleaned with ethanol, acetone, and deionized water and dried at $80^{\circ} \mathrm{C}$ prior to use. Molybdenum thin films were deposited onto $\mathrm{Si}(100)$ and borosilicate glass.

2.3 Synthesis of $\mathrm{MoO}_{3}$ thin films.

Post-annealing of the $\mathrm{MoO}_{3}$ films was carried out at $400{ }^{\circ} \mathrm{C}$ for $2 \mathrm{~h}$ under a continuous flow of synthetic air in a programmable Lindberg tube furnace and then allowed to slowly return to room temperature.

2.4 Synthesis of AuNPs on $\mathrm{MoO}_{3}$ thin films.

AuNPs were deposited onto $\mathrm{MoO}_{3}$ thin films by Magnetron Sputtering 
with a DC diode sputtering single source. The equipment used was a Magnetron Sputter Coater Pelco SC-6 with a gold target $(99.99 \%)$. Pre-deposited $\mathrm{MoO}_{3}$ thin films were introduced into the vacuum chamber at a pressure of $0.05 \mathrm{mbar}$. Argon was used for sputtering with an ionization current of $25 \mathrm{~mA}$ and the gold foil as the cathode. The deposition times were 1, 2, 3, 4, 5 and $20 \mathrm{~s}$, and the $\mathrm{MoO}_{3}$ film was maintained at constant pressure.

\section{RESULTS AND DISCUSSION}

3.1 Synthesis and characterization of Au NPs onto $\mathrm{MoO}_{3}$ thin films

The formation of AuNPs on the $\mathrm{MoO}_{3}$ surface was confirmed by monitoring the UV/Vis absorption band associated with the surface plasmon resonance (SPR). SPR absorption band measurements provide information about the presence and estimated size of the AuNPs on the oxide film. This method was used to evaluate the effects of different sputtering times on the deposition of gold NPs and to determine the optimum deposition time ${ }^{1,28}$. Surface plasmon absorption spectra of spherical gold nanoparticles prepared by DC-sputtering for different deposition times are shown in Fig 1. As observed from the figure, the absorption spectrum maximum is shifted from $560 \mathrm{~nm}$ for NPs produced by $3 \mathrm{~s}$ of sputter depositing to $585 \mathrm{~nm}$ for NPs produced during a 5-s deposition.

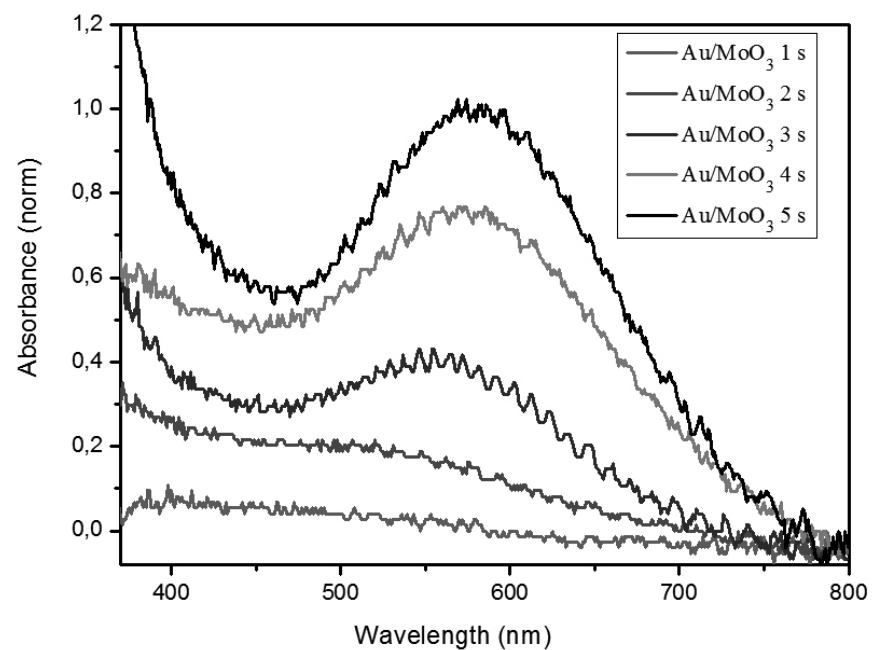

Fig. 1 UV/Vis surface plasmon resonance absorption of gold nanoparticles deposited onto $\mathrm{MoO}_{3}$ thin films by DC-magnetron sputtering with different deposition times.

The bathochromic shift is also accompanied by a broadening of the band and an increase in the intensity, which is associated with an increase in the diameter and number of the gold particles. This could also result from NP aggregation or an interparticle coupling phenomenon produced by the proximity of metal NPs ${ }^{42}$. As a consequence, NPs that are arranged side by side behave as a single, larger structure with a collective effect on the plasmon resonance. Longer sputtering times were evaluated; however, the surface plasmon effect was lost, likely because of an excess of AuNPs.

SEM studies showed that nanoparticles deposited under these conditions have an apparent spherical shape and were homogeneously dispersed on the surface layer of oxide (Fig. 2a). Increasing the time of sputtering produces an increase in the size of the NPs. The average size of the Au particles that formed using a 5-s deposition, as determined by a size distribution study of the SEM image, was measured to be $18 \mathrm{~nm}$, with a relatively narrow size distribution (histogram Fig. 2c). SEM images and their respective histograms show dispersity of nanostructure sizes. Therefore, $5 \mathrm{~s}$ corresponds to the optimum deposition time. As previously discussed, the increase in bandwidth and the absorption band shift towards higher wavelengths are the result of a dipolar coupling between closely spaced particles ${ }^{28,43,44}$. NP aggregations on the oxide surface are observed for samples that were subjected to $20 \mathrm{~s}$ of sputter depositing, as shown in the SEM image (Fig. 2b), and have an average particle size of $460 \mathrm{~nm}$, as determined by the particle size distribution (histogram, Fig. $2 d)$. (a)

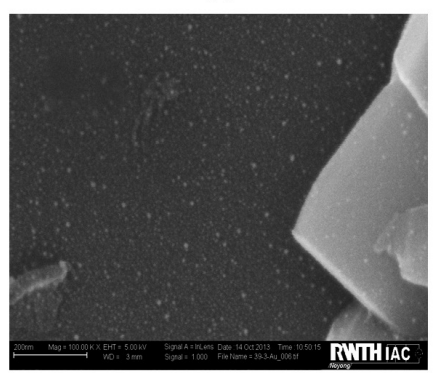

(c)
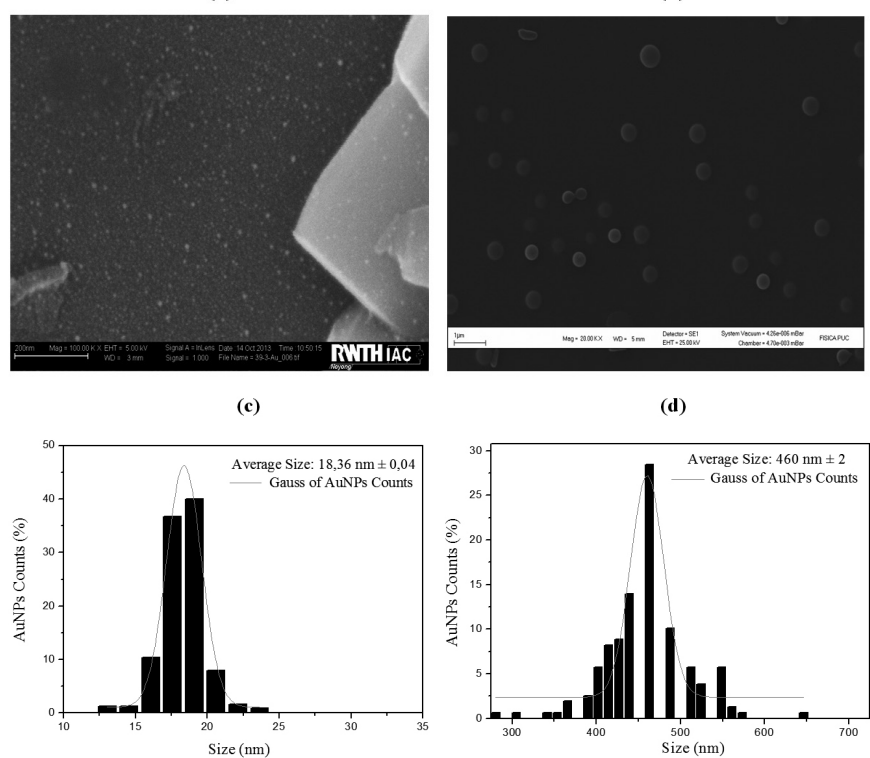

(d)

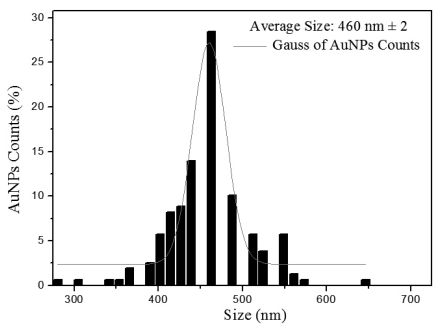

Size $(\mathrm{nm})$

Fig. 2 SEM images of $\mathrm{MoO}_{3}$ films doped with AuNPs (a) deposition time $=$ $5 \mathrm{~s} /$ Mag. $=100.000 \mathrm{x}(\mathbf{b})$ deposition time $=20 \mathrm{~s} /$ Mag. $=20,000 \mathrm{x}$. Histograms of particle size distribution for the $\mathrm{AuNP} / \mathrm{MoO}_{3}$ films (c) deposition time $=5 \mathrm{~s}$ and (d) deposition time $=20 \mathrm{~s}$

To obtain information concerning the chemical state of the AuNPs, the samples were characterized by XPS. The low-resolution XPS spectrum of a sample that contained 18-nm AuNPs (Fig. 3) shows the characteristic signals of $\mathrm{O}$ and $\mathrm{Mo}$ for the support and the signal of Au for the AuNPs, thus confirming the presence of metal in the film. The signal intensity was significantly lower for $\mathrm{Mo}$ and $\mathrm{O}$ than for $\mathrm{Au}$, which was the predominant species in the test area. The presence of the $\mathrm{C} 1 \mathrm{~s}$ signal is associated with the adsorbed carbon impurities on the surface of the film.

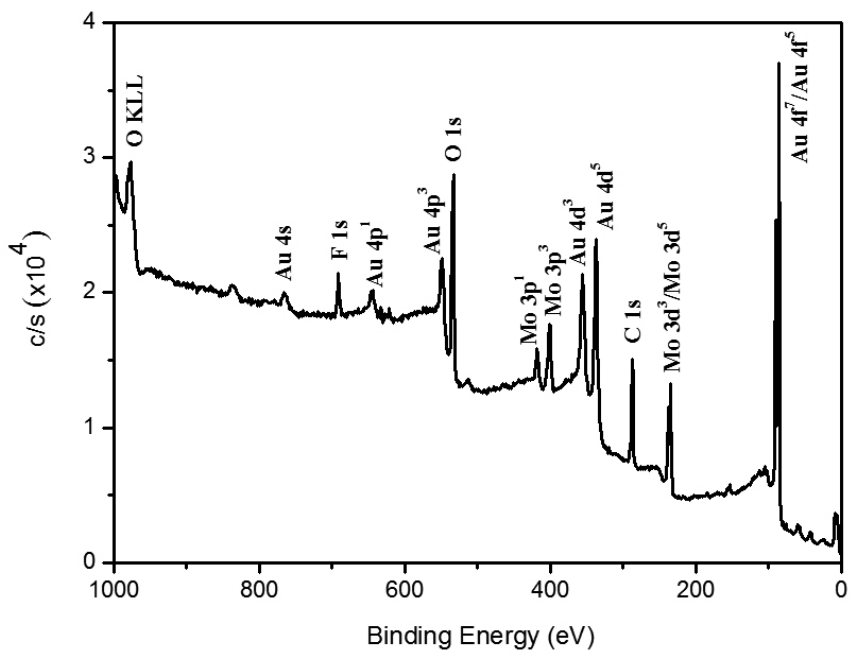

Fig. 3 Wide-scan XPS spectrum of an $\mathrm{Au} / \mathrm{MoO}_{3}$ thin film (sputtering time $=5 \mathrm{sec})$.

The high-resolution spectra of the Au $4 \mathrm{f}$ lines (Fig. 4a) show one doublet located at 83.9 and $87.5 \mathrm{eV}$, which correspond to $\mathrm{Au} 4 \mathrm{f}_{7 / 2}$ and $\mathrm{Au} 4 \mathrm{f}_{5 / 2}$, respectively. These values are in agreement with the data reported by other authors ${ }^{45}$ and indicate that the chemical species present in the film corresponds to $\mathrm{Au}(0)$, without other satellite signals ${ }^{45-49}$. 

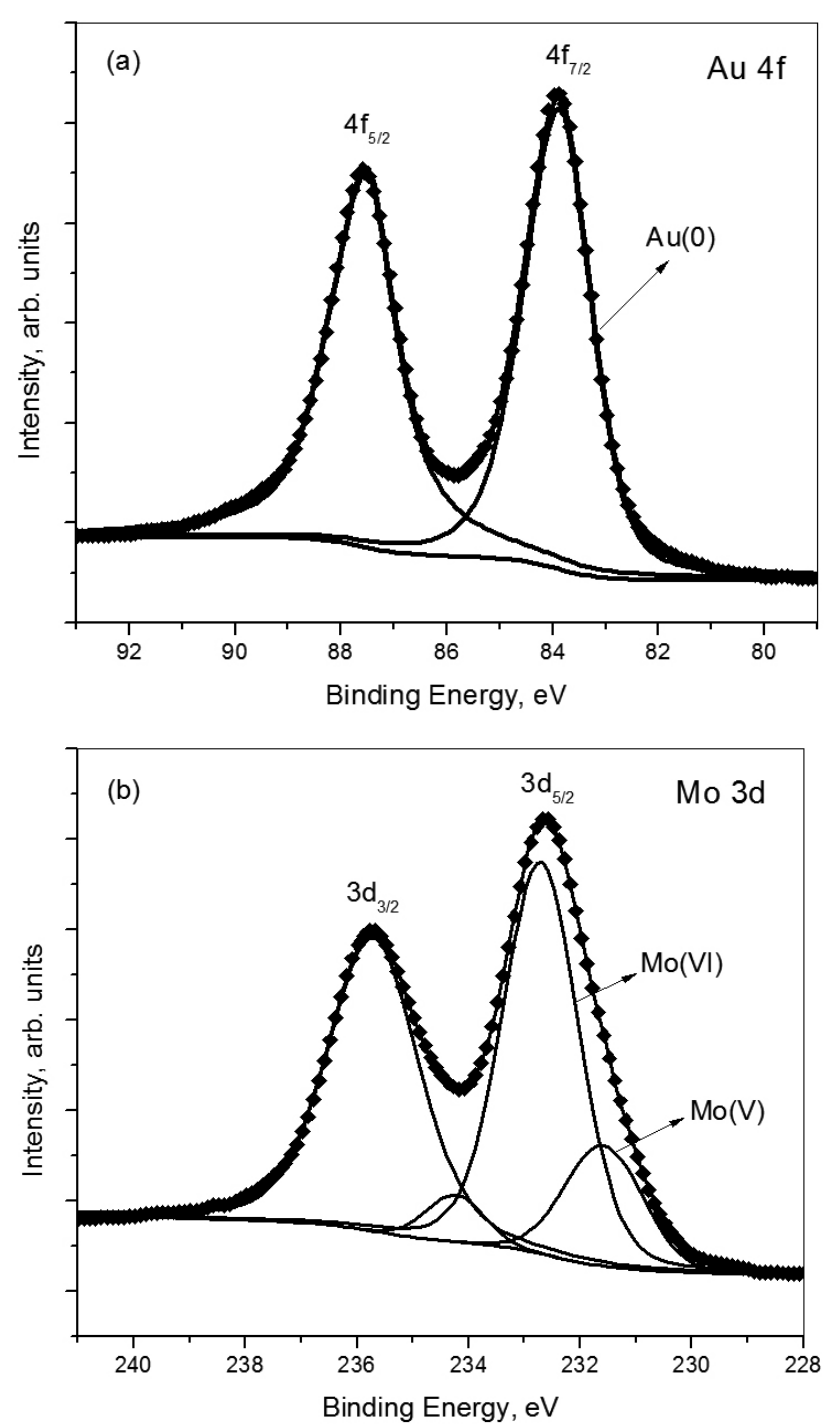
Mo $3 \mathrm{~d}$

Fig. 4 High-resolution XPS spectra of $\mathrm{Au} / \mathrm{MoO}_{3}$ films (a) $\mathrm{Au} 4 \mathrm{f}$ and (b)

For the case of Mo 3d (Fig. 4b, Table 1) the predominant species (>90\%) corresponds to Mo (VI), with binding energies of $232.7 \mathrm{eV}$ for Mo $3 \mathrm{~d}_{5 / 2}$ and $235.7 \mathrm{eV}$ for Mo $3 \mathrm{~d}_{3 / 2}{ }_{50-54}$. The presence of signals assigned to Mo(V) species at $231.6 \mathrm{eV}$ for $\mathrm{Mo} 3 \mathrm{~d}_{5 / 2}$ and $234.4 \mathrm{eV}$ for Mo $3 \mathrm{~d}_{3 / 2}$, could be explained by the over-irradiation of the photodeposited oxide or the catalytic action of the noble metal on the $\mathrm{MoO}_{3}$ surface. Finally, the $\mathrm{O}$ 1s peak shows the same composition as that determined for $\mathrm{MoO}_{3}$ films without $\mathrm{Au}$ doping, with an oxygen contribution from the oxide in the film and from adsorbed $\mathrm{OH}^{41}$.

Table 1 Standard binding energies for Mo $3 \mathrm{~d}$ photoelectron peaks associated with different oxidation states ${ }^{50}$.

\begin{tabular}{|c|c|c|c|c|}
\hline \multirow{2}{*}{ Oxidation State } & \multicolumn{2}{|c|}{ Standard Values $( \pm 0.1 \mathrm{eV})$} & \multicolumn{2}{|c|}{ Experimental Values $(\mathrm{eV}$} \\
\hline & Mo $3 d_{5 / 2}$ & Mo $3 d_{3 / 2}$ & Mo 3d & Mo 3d \\
\hline $\mathrm{Mo}(\mathrm{VI})$ & 232.5 & 235.7 & 232.7 & 235.7 \\
\hline $\mathrm{Mo}(\mathrm{V})$ & 231.5 & 234.7 & 231.6 & 234.4 \\
\hline Mo(IV) & 230.1 & 233.3 & & \\
\hline $\mathrm{Mo}(\mathrm{III})$ & 229.3 & 232.5 & & \\
\hline Mo(II) & 228.4 & 232.6 & & \\
\hline $\mathrm{Mo}^{0}$ & 227.7 & 230.9 & & \\
\hline
\end{tabular}

The crystal structure of the AuNPs was studied by XRD. The diffractogram of an $\mathrm{Au} / \mathrm{MoO}_{3}$ film with $470 \mathrm{~nm}$ NPs (Fig. 5a) clearly shows the presence of orthorhombic $\alpha-\mathrm{MoO}_{3}$ preferentially oriented along the [020] axis ${ }^{55-57}$, but no signals attributed to the gold NPs can be observed. This is likely due to a combination of factors, including the small particle size, the small grain size, and the relatively low concentrations of $\mathrm{Au}$ relative to $\mathrm{MoO}_{2}$. However, an XRD diffractogram using a grazing incidence angle (Fig. 6b) shows diffraction peaks at $2 \theta=38.2^{\circ}$ for the flat $\mathrm{Au}(111), 2 \theta=44.2^{\circ}$ for $\mathrm{Au}(200)$ and $2 \theta=64.9^{\circ}$ for $\mathrm{Au}$ (220), in accordance with the literature (JCPDS No. 04-0784). These results suggest that $470 \mathrm{~nm}$ AuNPs would exhibit a face centered cubic (fcc) structure ${ }^{24,58}$.
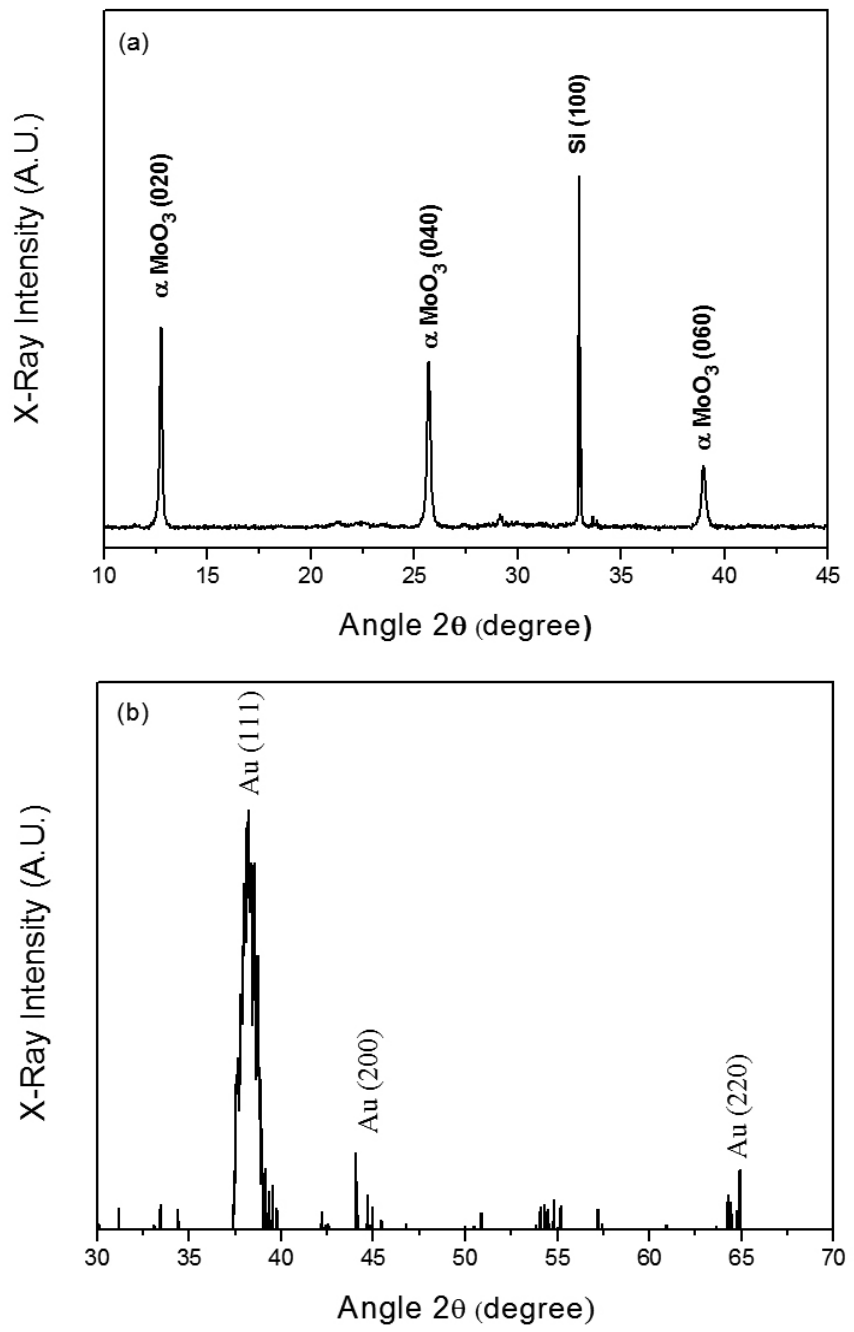

Fig. 5 XRD spectra of a $\mathrm{MoO}_{3}$ film (annealed at $400^{\circ} \mathrm{C}$ for $2 \mathrm{~h}$ ) doped with $470 \mathrm{~nm}$ AuNPs deposited by magnetron sputtering, (a) measured with the Bragg-Brentano instrumental function and (b) with grazing incidence.

\subsection{Optical Properties}

The variation in absorbance spectra of the $\mathrm{MoO}_{3}$ thin films doped with AuNPs is indicative of changes in the optical properties of the films. The optical band gap of the films can be estimated from the Tauc equation using their absorption spectra measured at room temperature. From solid-state band theory, the relation between the absorption coefficient $\alpha$ and the energy of the incident light $h v$ is given by

$$
(\alpha h v)=A\left(h v-E_{g}\right)^{n}
$$

where $A$ is the probability parameter for the transition and $E_{\mathrm{g}}$ is the optical band gap energy. For allowed direct transitions, the coefficient $\mathrm{n}=2$, and for allowed indirect transitions, $\mathrm{n}=1 / 2$. The values of $E_{\mathrm{o}}$ are estimated from the intersection of the extrapolated linear part of the $\left(\alpha \mathrm{hv}^{2}\right)^{2}$ curves with the 
energy axis (Fig. 6). The optical band gaps computed from the above relation are estimated to be 3.60 and $3.21 \mathrm{eV}($ when $\mathrm{n}=2$ ) for undoped and AuNP doped $\mathrm{MoO}_{3}$ films, respectively. The value of the optical band-gap energy for the undoped $\mathrm{MoO}_{3}$ film is in good agreement with the reported values for this non-stoichiometric oxide ${ }^{53,54,57}$. Once $\mathrm{MoO}_{3}$ films are doped with AuNPs, the band gap decreases to $3.21 \mathrm{eV}$. A possible explanation is that the deposition of catalytic metal nanoparticles forms additional intermediate electronic states in the metal oxide, which reside between the top of the valence band and the bottom of the conduction band ${ }^{13,59}$.

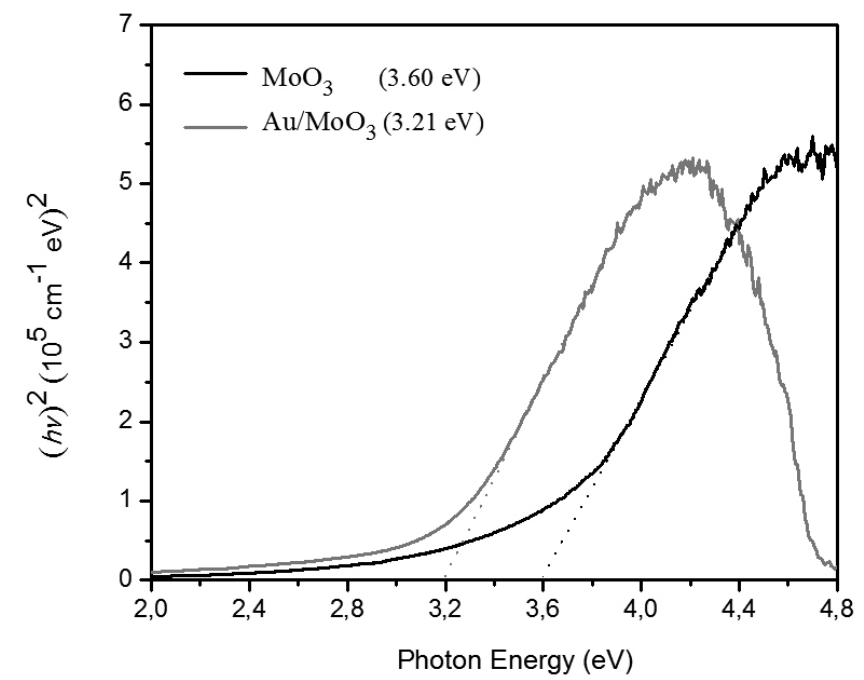

Fig. 6 Optical Band-Gap of $\mathrm{MoO}_{3}$ thin films undoped and doped with AuNPs.

\section{CONCLUSIONS}

The results of our studies demonstrate that the deposition of gold nanoparticles onto $\mathrm{MoO}_{3}$ films can be successfully achieved by a combination of PMOD and DC-magnetron sputtering methods. AuNPs with an average size of $18 \mathrm{~nm}$ formed after 5-s sputter depositing, and their size was directly related to the time used in the sputtering process. Increased deposition time caused significant particle growth, which reached $460 \mathrm{~nm}$ after a 15-s deposition. XRD using grazing incidence angle indicated that the $\mathrm{Au}$ in the $\mathrm{Au} / \mathrm{MoO}_{3}$ films exhibited a monocrystalline face-centered cubic structure. The gold possessed a single oxidation state, $\mathrm{Au}(0)$, as determined by high-resolution XPS analysis. XRD analysis also showed the presence of orthorhombic $\alpha-\mathrm{MoO}_{3}$ with a (020) preferential orientation. XPS surface analysis demonstrated the different contributions of $\mathrm{Mo}(\mathrm{VI})$ and $\mathrm{Mo}(\mathrm{V})$ oxidation states present in the thin film. Finally, gold doping caused a decrease in the $\mathrm{MoO}$ optical bandgap, which was probably due to the formation of intermediate electronic states. The gasochromic performance of the AuNP doped $\mathrm{MoO}_{3}$ films towards $\mathrm{H}_{2}$ gas is currently being investigated by our group. We expect that the deposition of Au nanoparticles on the $\mathrm{MoO}_{3}$ thin films will significantly improve the gasochromic properties of such films by increasing the sensitivity to $\mathrm{H}_{2}$, improving the dynamic optical performance, and lowering the operating temperature.

\section{ACKNOWLEDGMENTS}

This research was supported by FONDECYT, Chile (Project No.1110439) and Pontificia Universidad Católica de Valparaíso (Project D.I. No. 125.756/11). C. Castillo thanks CONICYT, Chile for a doctoral fellowship and doctoral thesis support (Project No 24110020). We also thank Dr. Michael Noyong of Institut für Anorganische Chemie at Aachen, for preparing the SEM images.

\section{REFERENCES}

[1] M. Daniel, D. Astruc, Chem. Rev. 104 293-346 (2004).

[2] P. Zhao, N. Li, D. Astruc, Coord. Chem. Rev. 257 638-665 (2013).

[3] M. Grzelczak, J. Perez-Juste, P. Mulvaney, L.Liz-Marz, Chem. Soc. Rev. 37 1783-1791 (2008).

[4] Juan J. Giner-Casares, Luis M. Liz-Marzán, Nano Today 9 365-377 (2014).
[5] A.K. Khan, R. Rashid, G. Murtaza, A. Zahra, Trop. J. Pharm. Res. 13 1169-1177 (2014).

[6] A. Liu, B. Ye, Clin. Lab. 59 23-36 (2013).

[7] R. Andres, T. Bein, M. Dorogi, S. Feng, J. Henderson, C. Kubiak, W. Mahoney, R. Osifchin, R. Reifenberge, Science 2721323 (1996).

[8] T. Okamoto, I. Yamaguchi, J. Phys. Chem. B 107 10321-10324 (2003).

[9] I. Sosa, C. Noguez, R. Barrera, J. Phys. Chem. B 107 6269-6275 (2003).

[10] J. Novak, L. Brousseau, F. Vance, R. Johnson, B. Lemon, J. Hupp, D. Feldheim, J. Am. Chem. Soc. 122 12029-12030 (2000).

[11] M. Ando, T. Kobayashi, S. Iijima, M. Haruta, J. Mater. Chem. 7 17791783 (1997)

[12] M. Ando, T. Kobayashi, S. Iijima, M. Haruta, Sens. Actuators B 96 589595 (2003).

[13] M. Ahmad, A. Sadek, M. Yaacob, D. Anderson, G. Matthews, V. Golovko, W. Wlodarski, Sens. Actuators B 179 125-130 (2013).

[14] T. Takei, K. Akita, I. Nakamura, T. Fujitani, M. Okumura, K. Okazaki, J.H. Huang, T. Ishida, M. Haruta, Adv. Catal. 55 1-126 (2012).

[15] C. Della Pina, E. Falletta, L. Prati, M. Rossi, Chem. Soc. Rev. $372077-$ 2095 (2008).

[16] A. Corma, H. Garcia, Chem. Soc. Rev. 37 2096-2126 (2008).

[17] Y. Zhang, X.J. Cui, F. Shi, Y. Deng, Chem. Rev. 112 2467-2505 (2012).

[18] M. Stratakis, H. Garcia, Chem. Rev. 112 4469-4506 (2012).

[19] S.E. Davis, M.S. Ide, R.J. Davis, Green Chem. 15 17-45 (2013).

[20] Y. Mikami, A. Dhakshinamoorthy, M. Alvaro, H. García, Catal. Sci. Technol. 3 58-69 (2013).

[21] D.V. Leff, P.C. Ohara, J.R. Heath, W.M. Gelbart, J. Phys. Chem. 99 7036-7041 (1995).

[22] M. Kaushik, Z.L. Wang, P. Tarasankar, J. Photoch. Photobio. A 14075 (2001).

[23] T.K. Sau, P. Anjali, N.R. Jana, Z.L. Wang, P. Tarasankar, J. Nanopart. Res. 3 257-261 (2001).

[24] N. Long, L. Vu, C. Kiem, S. Doanh, C. Nguyet, P. Hang, N. Thien, L. Quynh, J. Phys. Conf. Ser. 187012026 (2009).

[25] O. Kenji, M. Yoshiteru, T.A. Yamamoto, M. Yasuaki, N.Yoshio, Mater. Lett. 613429 (2007).

[26] L. Cuncheng, C Weiping, K. Caixia, F. Ganhua, Z. Lide, Mater. Lett. 58 196 (2003).

[27] W. Liping, M. Wei, N. Dandan, D. Junwei, W. Ying, T. Yifeng, Electrochem. Commun. 10673 (2008).

[28] L. Barrientos, N. Yutronic, F. del Monte, M. Gutiérrez, P. Jara, New. J. Chem. 31 1400-1402 (2007).

[29] G. Veith, A. Lupini, S. Pennycook, G. Ownby, N. Dudney, J. Catalysis 231 151-158 (2005).

[30] P. Kelly, R. Armell, Vacuum 56(3) 159-172 (2000).

[31] D.B. Akolekar, K. Bhargava, G. Foran, M. Takahashi, J. Mol. Catal. A-Chem. 238 78-87 (2005).

[32] M. Baron, O. Bondarchuk, D. Stacchiola, S. Shaikhutdinov, H.-J. Freund, J. Phys. Chem. C, 113, 6042-6049 (2009).

[33] S. Lee, C. Fan, T. Wu, S. L. Anderson, Surface Science 578 5-19 (2005).

[34] Á. Kukovecz, G. Pótári, A. Oszkó, Z. Kónya, A. Erdőhelyi, J. Kiss, Surface Science 605 1048-1055 (2011).

[35] P. Pusztai, R. Puskás, E. Varga, A. Erdohelyi, A. Kukovecz, Z. Konya, J. Kiss, Phys. Chem. Chem. Phys. 1626786 (2014)

[36] M. Haruta, Chem. Record 375 (2003).

[37] M. Okumura, T. Akita, M. Haruta, X Wang, O. Kajikawa, O. Okada, Appl. Catal. B: Environmental 41- 43( 2003).

[38] K. Saha, S.S. Agasti, C. Kim, X. Li , M. Vincent, Chem. Rev. 112(5) 2739-2779 (2012)

[39] T. He, Y. Ma, Y. Cao, J. Peng, X. Zhang, W. Yang, J. Yao, Langmuir 17: 8024-8027 (2001)

[40] G.E. Buono-Core, A. Klahn, C. Castillo, E. Muñoz, C. Manzur, G. Cabello, B. Chornik, J. Non-Cryst. Solids 387 21-27 (2014).

[41] D.A. Shirley, Phys. Rev. B 5 4709-4714 (1972).

[42] Y. Hatakeyama, K. Onishi, K. Nishikawa, RSC Advances 1 1815-1821 (2011).

[43] K. Su, Q. Wei, X. Zhang, J. Mock, D. Smith, Nano Lett. 3 1087-1090 (2003).

[44] S. Ghosh, T. Pal, Chem. Rev. 107 4797-4862 (2007).

[45] R.G. Palgrave, I.P. Parkin, Chem. Mater. 19 4639-4647 (2007).

[46] H. Wei, J. Li, J. Zheng, H. Su, X. Wang, Inorg. Chim. Acta 427 33-40 (2015).

[47] M. Casaletto, A. Longo, A. Martorana, A. Prestianni, A. Venezia, Surf. Interface Anal. 38 215-218 (2006). 
[48] L. Ono, B. Roldan-Cuenya, J. Phys. Chem. C 112 4676-4686 (2008) .

[49] N. Turner, A. Single, Surf. Interface Anal. 15 215-222 (1990).

[50] S. Sunu, E. Prabhu, V. Jayaraman, K. Gnanasekar, T. Seshagiri, T. Gnanasekaram, Sens. Actuators B 101 (2004) 161-174.

[51] O. Hussain, K. Rao, Mater. Chem. Phys. 80 638-646 (2003).

[52] R. Cardenas, J. Torres, J. Alfonso, Thin Solid Films 478 146-151 (2005).

[53] J. Dupin, D. Gonbeau, P. Vinatier, A. Levasseur, Phys. Chem. Chem. Phys. 2 1319-1324 (2000).

[54] A. Bouzidi, N. Benramdane, H. Tabet-Derraz, C. Mathieu, B. Khelifa, R. Desfeux, Mater. Sci. Eng. B 97 5-8 (2003).
[55] G.E. Buono-Core, G. Cabello, A. Klahn, A. Lucero, M.V. Nuñez, B. Torrejón, C. Castillo, Polyhedron 29 1551-1554 (2010).

[56] T. Chiang, H. Yeh, J. Alloys Compd. 585 535-541 (2014).

[57] M. Dhanasankar, K. Purushothaman, G. Muralidharan, Appl. Surf. Sci. 257 2074-2079 (2011).

[58] Y. Chen, X. Gu, C. Nie, Z. Jiang, Z. Xie, Chem. Commun. 4181-4183 (2005).

[59] D. Kaczmarek, J. Domaradzki, E. Prociow, T. Berlicki, K. Prociow, Opt. Mater. 31 1337-1339 (2009). 